\title{
Review: verteporfin plus photodynamic therapy reduces loss of vision in age related macular degeneration
}

Wormald R, Evans J, Smeeth L, et al. Photodynamic therapy for neovascular age-related macular degeneration. Cochrane Database Syst Rev 2003;(3):CD002030 (latest version 25 Feb 2003).

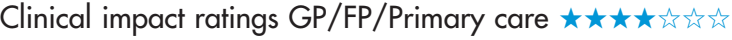

In patients with neovascular age related macular degeneration (AMD), what is the effect of photodynamic therapy?

METHODS

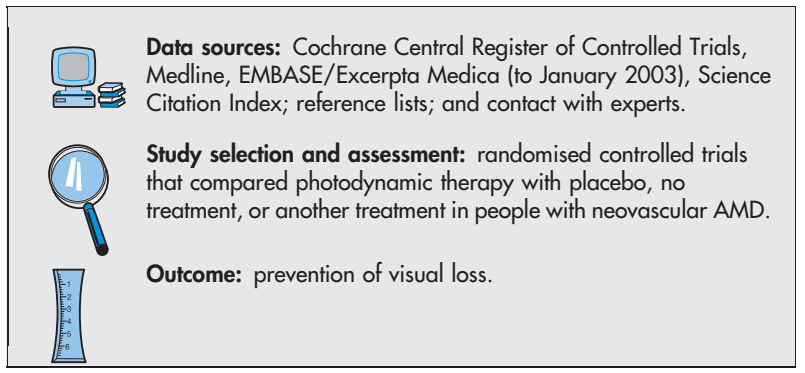

\section{MAIN RESULTS}

2 studies (948 participants) were included. Both studies compared verteporfin, $6 \mathrm{mg} / \mathrm{m}^{2}$ (intravenous infusion of $30 \mathrm{ml} / 10 \mathrm{~min}$ ), plus photodynamic therapy with placebo plus photodynamic therapy. Data were pooled using a fixed effects model. At 24 months, fewer people in the verteporfin group than in the placebo group lost $\geqslant 3$ lines or $\geqslant 6$ lines of vision (table). More people treated with verteporfin than with placebo reported visual disturbances, problems with the injection site, infusion related back pain, and photosensitivity reactions (table). Allergic reactions were similar in both groups.

\section{CONCLUSION}

In people with neovascular age related macular degeneration, the addition of verteporfin to photodynamic therapy reduced visual loss.

For correspondence: MrR Wormald, Moorfields Eye Hospital and Institute of Ophthalmology, London, UK. r.wormald@ucl.ac.uk

Source of funding: no external funding.

\section{Commentary}

$\Delta$ $M D$ is the leading cause of legal blindness in the US among people over the age of 65 years; the risk of developing the disease increases with age. ${ }^{12}$ Limited treatment options are available for this disorder. The Age-Related Eye Disease Study-an NIH sponsored, multicentre, placebo controlled trial-examined the beneficial effects of high dose zinc and vitamin antioxidants on the progression of AMD. ${ }^{3}$ Prophylactic laser treatment of patients with high risk large drusen is also being evaluated. Laser photocoagulation treatment of choroidal neovascularisation (CNV) secondary to AMD has shown some benefit for patients, but disease recurrence rates are high within 3 years. ${ }^{12}$

The studies in the review by Wormald et al involved elderly patients (mean age $75 \mathrm{y}$ ) with either "classic" CNV or occult CNV and significant recent worsening of vision and found improvement in visual acuity with photodynamic therapy. Photodynamic therapy offers the advantage of a treatment targeted specifically at the proliferating neovascularisation while avoiding collateral injury. Currently, not all patients with wet AMD are candidates for this therapy, and it is recommended for eyes with predominantly classic subfoveal CNV. Verteporfin is contraindicated for patients with porphyria.

Other treatments under investigation for $A M D$ include vitreoretinal microsurgical techniques, medical therapy targeting growth factors, and experimental drugs. Visual rehabilitation programmes remain beneficial.

Blindness is not an inevitable outcome of AMD. As new treatments become available, early detection may allow for maximal preservation of vision

Suzanne Fields, MD State University of New York at Stony Brook Stony Brook, New York, USA

1 Gottlieb JL. Age-related macular degeneration. JAMA 2002;288:2233-6.

2 Mittra RA, Singerman $U$. Recent advances in the management of agerelated macular degeneration. Optom Vis Sci 2002;79:218-24.

3 Sackett CS, Schenning S. The age-related eye disease study: the results of the clinical trial. Insight 2002;27:5-7.

Verteporfin $v$ placebo before dynamic phototherapy for neovascular age related macular degeneration*

\begin{tabular}{|c|c|c|c|c|}
\hline \multirow[b]{2}{*}{ Outcomes } & \multicolumn{2}{|c|}{ Weighted event rates } & \multirow[b]{2}{*}{$\operatorname{RRR}(95 \% \mathrm{Cl})$} & \multirow[b]{2}{*}{ NNT (Cl) } \\
\hline & Verteporfin & Placebo & & \\
\hline \multirow{2}{*}{$\begin{array}{l}\geqslant 3 \text { lines of vision lost at } 24 \text { months } \\
\geqslant 6 \text { lines of vision lost at } 24 \text { months }\end{array}$} & $50 \%$ & $64 \%$ & $23 \%$ (13 to 31$)$ & $8(5$ to 13$)$ \\
\hline & & & RRI (CI) & NNH (Cl) \\
\hline $\begin{array}{l}\text { Visual disturbances } \\
\text { Problem with injection site } \\
\text { Infusion related back pain } \\
\text { Photosensitivity reactions }\end{array}$ & $\begin{array}{l}29 \% \\
13 \% \\
2.0 \% \\
2.3 \%\end{array}$ & $\begin{array}{l}18 \% \\
5.6 \% \\
0 \% \\
0.3 \%\end{array}$ & $\begin{array}{r}61 \%(24 \text { to } 109) \\
134 \%(43 \text { to } 282) \\
721 \%(9 \text { to } 6060) \\
431 \%(0 \text { to } 2717)\end{array}$ & $\begin{array}{l}10 \text { (6 to } 17) \\
15(10 \text { to } 25) \\
50(25 \text { to } 100) \\
50(25 \text { to } 100)\end{array}$ \\
\hline
\end{tabular}

*Abbreviations defined in glossary; weighted events, RRR, RRI, NNH, and Cl calculated from data in article. 